\title{
A Multivariate Analysis Of Evoked Sets As A Marketing Universal
}

Ronald P. LeBlanc, (E-mail: leblron@isu.edu), Idaho State University Neil C. Herndon, Jr., Hofstra University

\begin{abstract}
This research explores evoked sets in two cultures. The purpose is to determine if evoked sets are used in both to the extent that they could be considered a marketing universal. Previous studies have examined marketing universals in terms of price and product quality signals. Our findings support the status of evoked sets as a marketing universal. We found, via multivariate analysis, that evoked set sizes are statistically equal for matched samples when using two operational definitions of an evoked set.
\end{abstract}

\section{Introduction}

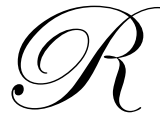

Tecently, researchers have empirically identified consumer behaviors that are relatively invariant across cultures. Dawar and Parker (1994) found several elements of product quality signaling for shopping goods that they have termed "marketing universals" -- consumer behaviors that are relatively invariant across cultures. Their research adds a new dimension to the standardization versus localization discussion that began in the 1980s and continues today (James and Hill, 1991; Kanso, 1992; Hite and Fraser, 1988). If marketing universals exist, the possibility for managers to use standardized marketing programs is enhanced. Evoked sets, also know as consideration sets or choice sets, continue to be a major topic of academic analysis. However, the research in this area has not addressed cross-cultural aspects of the size, formation, or use of evoked sets. The specifics of whether or not culture influences this micro-level aspect of the consumer decision-making has received little attention in the empirical literature.

Given the strategic and managerial importance of a brand's presence or absence in a consumer's evoked set, this area is a potentially fruitful area for exploration. Brands outside the evoked set do not make it into the consumer's evaluation stage in the decision making process and, therefore, have no possibility of being purchased. A managerial understanding of consumers' development of evoked sets and the choices made from within the evoked sets can aid management in better understanding consumer choice processes. The purpose of this research is to explore the existence of evoked sets as a marketing universal by evaluating evoked set size for a shopping good in a cross-cultural context. Equality of size across cultural boundaries would suggest evoked sets are a marketing universal.

\section{Marketing Universals}

Managers operating internationally have two main strategic choices. The first is the use of a standardized marketing strategy. A standardized approach is appropriate when consumer decision-making processes across the countries are independent of cultural differences. The second is to use an adaptive strategy. Using this strategy, the manager treats each country in which the company sells its products as a unique market segment because of actual or perceived differences in consumer behavior.

Both managerial approaches depend on the underlying models of consumer behavior. Sellers, via marketing research or experience, assume buyers in different cultures are using similar or dissimilar models of

Readers with questions or comments are encouraged to contact the authors via email. 
buying behavior. If similarities exist among market segments in different cultures and relevant consumer behavior can be shown to be culturally independent, a standardized marketing strategy is appropriate. The assumption of consumers using different decision-making behaviors leads management to approach the markets as different segments or target markets.

Managers must balance the need to segment between using cultural criteria and using individual consumer characteristics consistent among groups in different cultures. Dawar and Parker (1994) addressed this issue by examining marketing universals in a study that included 38 mostly Western industrialized countries and Japan, showing consumer behaviors that are relatively invariant across cultures. They found, for consumer electronics (video cameras, video cassette recorder, digital audio tape recorder, and HD TV), brand name, price, physical appearance, and retailer reputation are universals. Consequently, they suggest that managers reinforce these brand signals to an equal degree across countries. They also caution that cultural differences in the use of media require using different media in different markets. They found that consumers use different media across cultures when gathering information about brands.

McGowan and Sternquist's (1998) study included Japanese and American students to study the psychometric properties of three different price scales. They found that the scales are reliable measures across the two countries and that for the homogenous groups in the two cultures the scales could be considered marketing universal behaviors. Pettit, Sawa, and Sawa (1985) found frugality, a price related factor, to be similar across two cultures -- U.S. and Jordanian.

The idea of marketing universals presumes that consumer decision-making processes are similar across cultures. The macro-models of Assael (1992), Engel, Blackwell, and Minard (1993), and Wilkie (1994) all recognize that culture plays a role in the consumer decision-making process. However, culture is viewed as an exogenous variable having some, but unspecified, impact on the consumer decision-making process. Discussions of culture's impact at the macro level revolve around differences in cultural values, norms, and sanctions as well as non-verbal communication issues. Little attention has been focused on how culture may influence specific stages of the consumer decision-making process, although Webster (1992) has shown ethnic identification does have a significant impact on information search patterns associated with advertising, reference groups, miscellaneous readership and in-store research.

Since the full range of ways in which culture influences consumer decision behavior is beyond the scope of a single study, to focus on one area that may yield interesting and useful insights for both researchers and managers is reasonable. Evoked sets are a concept introduced into the consumer behavior literature by Howard (1963). He recognized that consumers do not evaluate all possible brands of a product when making a purchase decision. He argued that consumers establish a subset of available brands from which they make purchase decisions. This topic has received independent examination in Europe and the United States. Cultural influences on evoked sets can only be implied by examining differences reported in the independently published research. One area of finding that is consistently reported is the size of the evoked set. The size of the evoked set in effect "limits" the number of brands that any consumer might consider for purchase.

\section{Evoked sets}

The idea that a consumer's choice is limited to a small number of brands was presented by Howard and Sheth (1969). The antecedent condition of an evoked set, the awareness set was identified by Narayana and Markin's (1975). The awareness set, all those brands consumers have knowledge of contains three subsets termed evoked, inert, and inept sets. The evoked set is the set of brands from which purchase choice will be made. A brand not in the evoked set has no chance of being purchased. The consumer has positive attitudes for this subset of brands. The inert set contains those brands of which consumers are aware but to which they hold neutral attitudes: brands in the inert set are not considered when making a purchase. The inept set contains brands that consumers are aware of but to which they hold negative attitudes: brands in the inept set are not considered for purchase. They suggested that the composition of the evoked set is decided over time as consumers become aware of and then classify brands into different sets. 
Evoked set decision-making processes over time were modeled by Turley and LeBlanc (1995). They describe a phased decision making process with evoked set composition decisions being mediated both by the consumer's post-purchase evaluations and by the seller's marketing efforts. Similarly, Lapersonne, Laurent, and LeGoff (1995) have found satisfaction with a previous purchase related to evoked set size.

Initial studies of evoked sets focused on size and found evoked set sizes to be small (Belonax and Mittelsteadt, 1978; Campbell, 1969, Jarvis and Wilcox, 1973; May and Homans, 1977;Ostland 1973; Silk and Urban, 1978). These studies, concentrating on convenience goods available at supermarkets, reported evoked set sizes that average 3.8 brands. Hauser and Wernerfelt (1990) reported evoked set sizes for twenty-three convenience goods categories with an average evoked set size of 4.1 brands.

Conflicting results are reported in studies of the evoked set sizes of shopping goods. Evoked set sizes reported for automobiles (Laspersonne, Laurent, and LeGoff, 1995; Gronhaug, 1973/74; Gronhaug and Troye, 1983; Hauser and Wernerfelt, 1990), stereo systems (Abougomaah, Schlacter, and Gaidis, 1987) and microwave ovens (Belonax and Mittelsteadt, 1978) range from 2.0 to 8.1. LeBlanc and Turley (1994) report evoked set sizes for twenty-three shopping goods average 2.19 brands. However, Baker and Wilkie (1992) suggest that consumers have even smaller evoked set sizes for shopping goods. They state, "consumers seem to have initial evoked sets with only a single brand in them ..." (p. 3). Others (Laspersonne, Laurent, and LeGoff, 1995) also describe an evoked set size of one for automobiles.

Cross-cultural comparison of evoked set sizes involve looking at the results from independent studies conducted ten years apart. A European study of automobile purchasing by Gronhaug and Troye (1983) indicates larger evoked set sizes for automobile purchases by European consumers than any reported by studies conducted in the United States (Ostlund, 1973).

\section{Approaches to Cross-Cultural Studies}

Researchers have used at least two approaches to assess the impact that culture plays in consumer decisionmaking. The approach espoused by Dawar and Parker (1994) matches target groups in two distinct cultures as a means of isolating the culture's impact on consumer decision-making. The argument for choosing representative samples from the target markets that marketers are pursuing, instead of randomly selecting from the general population, is that this approach provides a better means of understanding cultural differences and identifying marketing universals (Dawar and Parker, 1994; Kale and Sudharshan, 1987).

Other studies that explore differences in behavior in several countries approached cross-cultural issues by taking random samples to seek statistical differences in means or variance in the samples (Brown and Wildt, 1992; Green and Langeard, 1975). This approach identifies statistical differences, but those identified may be from factors unrelated to cultural differences (Lorimer and Dunn, 1968; Clark, 1990). Despite the theoretical reduction in generalizability in favor of increases in statistical power (Cook and Campbell, 1979) when matched groups are used, the matching process is adopted for our study.

Identification of marketing universals across cultures can be done on three levels -- existence of behavior, relative importance, and absolute level of behavior -- but requires, from a statistical perspective, that no differences exist at the absolute level (Dawar and Parker, 1994). This means that if evoked sets are a marketing universal, there should not be statistical differences in evoked set sizes between the matched samples.

This leads to the following null hypothesis statement:

Ho: The evoked set sizes are invariant (equal) in the matched target market groups. 


\section{Methodology}

The researchers selected a product for study in the category of shopping goods that is a standard item in the inventory of college students -- athletic shoes. Male and female students use athletic shoes both in a functional manner and as a fashion statement. Athletic shoes are used for exercise and sports activities and serve as a mainstay in the daily dress of students. They are also a costly product for the college student with shoe prices as high as USD $\$ 150.00$. This cost factor places the product in a high involvement category with the purchaser able to remember details of the purchase decision-making process.

Two matched groups of students were respondents in the survey. The first group consisted of students in a state university located in the northwestern United States. The second group of respondents attends one of the universities in Hong Kong where instruction is in English; consequently, translating the questionnaire into Chinese for these students was not necessary. Respondents in both samples were personally interviewed by a trained group of student researchers. Because the selected respondents were representative of major target markets in each country, a convenience sample from this matched set was taken.

In the personal interviews, respondents were approached by the trained researchers and first asked for their cooperation. Then, they were screened to learn whether they had purchased athletic shoes in the prior three months. Only respondents who had made a recent purchase (i.e., prior three months) were interviewed to minimize forgetting, even though the product is a good that engenders high involvement.

Respondents were asked open-ended questions to identify the brands that they had considered purchasing and the brands that they had actually tested by wearing them in the store. Different models of the same brand were not considered different brands, so coding the data required only counting the reported number of brands considered and the number of brands tried on.

The two operational measures of evoked set size -- number of brands considered and number of brands tried on -- were used because the operational definition of the evoked set appears to have an influence on respondents' statement of the set size (Baker and Wilkie, 1992). While Narayana and Markin (1975) treat the evoked set as brands considered, Shocker et al (1991) treat it as brands evaluated at the point of decision-making. Using two measures allows both definitions to be considered in the search for marketing universals. This assumes that a respondent's trying on shoes is representative of evaluative behavior.

Students are appropriate subjects for this type of study for at least two reasons. First, students are a matched group producing a homogenous sample set. Second, students in this case are not serving as surrogates for analytical purposes. This research project focuses on students because they are a primary target for athletic shoes. Also students are a group suitable for discovering elements of consumer decision-making that may also apply to larger segments of the population. The United States was selected to provide a basis for comparisons since most normative marketing theory was developed in that country. Hong Kong was selected for the Asian comparison because of the current interest in Chinese markets by consumer goods manufacturers. The questionnaire used in the survey was developed after a series of focus group interviews with college students in the United States. The questionnaire was pre-tested in both countries and subsequently revised.

MANOVA was used to test the hypothesis as the two measures of evoked set size are expected to be correlated. MANOVA allows for the testing of the equality of the vector means using the two measures of evoked set size. A 99\% level of confidence is being used because the sample sizes are large and this would make small differences in sample means, which are not of practical interest, statistically different.

\section{Findings}

The survey resulted in 104 usable questionnaires from the sample in the United States and 190 from the sample in Hong Kong. The mean values for the two groups are: 
Table 1

Sample Means

\begin{tabular}{|c|c|c|c|}
\hline Country & N & Mean & Std. Deviation \\
\hline Considered & & & \\
U.S. & 104 & 3.20 & 1.30 \\
Hong Kong & 190 & 3.04 & 1.30 \\
\hline Tried on & & & \\
U.S. & 104 & 2.59 & 1.12 \\
Hong Kong & 190 & 2.20 & 1.13 \\
\hline
\end{tabular}

The next analysis performed was a check on the level of correlation between the two measures of evoked set size. The result was a correlation of .6495 with a $p=.000$. This significant positive correlation between the two dependent variables used to measure the size of the evoked sets supports the use of MANOVA to test the equality of the vector means.

The results of the MANOVA test on the vector means is presented in the following table.

Table 2

Multivariate Test

\begin{tabular}{|l|l|l|l|l|l|}
\hline Country & Value & F & Hypothesis df & Error df & Sig. \\
\hline Hotelling's T & .031 & 4.512 & 2 & 291 & .012 \\
\hline
\end{tabular}

Tests of Between-Subjects Effects

\begin{tabular}{|l|l|l|l|l|l|}
\hline Source & Sum of Squares & df & Mean Square & F & Sig. \\
\hline Consider & 1.717 & 1 & 1.717 & 1.010 & .316 \\
\hline Tried & 10.042 & 1 & 10.042 & 7.891 & .005 \\
\hline
\end{tabular}

At a 99\% level of confidence, Hotelling's T test statistic for the difference in the vector means cannot be rejected.

\section{Discussion}

Both Western and Chinese consumers have evoked sets to which they refer when asked to express brand preferences for shopping goods. The multivariate solution shows that the mean force vector of the two correlated measures of number of brands considered for the matched samples was found to be equivalent between the two cultures. This suggests that evoked sets size may be considered a marketing universal.

The small size of the evoked sets for this shopping good is consistent and is in the lower range of other studies cited previously (Abougomaah, Schlacter, and Gaidis, 1987; Belonax and Mittelsteadt, 1978; LeBlanc and Turley, 1993). Also, this is the second study of a shopping good that finds evoked set sizes larger than a single brand (Lapersonne, Laurent, and LeGoff, 1995; Baker and Wilkie, 1992).

A previous study (Dawar and Parker, 1994) found product quality signals for shopping goods (video cameras, video cassette recorder, digital audio tape recorder, and HD TV) independent of cultural influence. These signals were called marketing universals. Like the Dawar and Parker study, our study found similarities between the buying behavior of consumers from the U.S. and Japan to be similar: both used evoked sets and both appear to use the same number of brands when evaluating alternatives.

\section{Limitations}

The results of this study should not be generalized to other goods, other target markets, and other cultures 
not included in the sample used for this study. The choice of the dependent variables for the measurement of evoked sets is dependent on the memory of the respondents. This limits the ability of researchers to see what is inside the black-box; hence we are forced to rely on the statements of respondents on the very important issue of the number of brands that were considered for a particular purchase. Analysis of the between-subjects effects indicates the number of brands tried on by the respondents would not have allowed its inclusion as a marketing universal if it had been tested alone.

\section{Managerial Implications}

Identification of evoked sets as a marketing universal allows marketing managers to treat both foreign and domestic markets as having invariant evoked set sizes. The marketing manager faces two conditions in either market -- the brand is either in or not in a potential consumer's evoked set.

Brands must be included in the target market's awareness set if the brand is to have any possibility of entering the evoked set. However, awareness is a necessary but not sufficient condition for the brand to be purchased. Inclusion of a brand in the evoked set heightens the possibility of a sale but, given the size of evoked sets, does not guarantee anything more than another evaluation. Managers need to understand what their target market desires from the product and to communicate clearly how the product satisfies these desires better than competitive offerings in order to increase their probability of consideration at the next purchase occasion.

New entrants to the market face a different problem. They must be able to break into an existing set of brands that the consumer already finds acceptable. When this occurs two possibilities exist: either the evoked set size is increased by one, or the new one displaces an existing brand. Which happens or what threshold level of differential advantage a new brand must attain so it will become a brand in the evoked set is not clear.

The battle that rages among many established brands may not be necessary. Many of the promotional efforts used to differentiate brands in the mind of consumers may be falling on deaf or at least indifferent ears if both brands are not in a person's evoked set. Recent moves by major convenience goods manufacturers to eliminate coupons from their promotional mix may reflect the cannibalization of sales from consumers' evoked sets. If all one accomplishes is stealing sales from competitors from what is a set of homogenous alternatives to the consumer, all one achieves is a lowering of the margin one might have otherwise gained if the sale were made at regular prices. Proctor and Gamble discovered this when it instituted its value pricing strategy in the mid-90's. By eliminating promotional pricing, Proctor and Gamble was able to be more profitable (Ailawadi, Lehmann, and Scott, 2001).

\section{Conclusion}

Evoked sets appear to be another element of consumer behavior that can be considered a marketing universal. Managers of multinational companies who find that a given aspect of consumer behavior does not vary across cultures are more likely to take the standardized approach to developing marketing strategies. Researchers are encouraged to expand the generalizability of these findings by examining other products in other cultures and to include additional factors such as those relating to the effects of store choice on evoked set size.

\section{References}

1. Abougomaah, N. H., J. L. Schlacter, and W. Gaidis, "Elimination and Choice Phases in Evoked sets Formation," Journal of Consumer Marketing, 4 (Fall), pp. 67-73, 1987

2. Ailawadi, K. L., D. R. Lemann, and S. A. Neslin, "Market Response to a Major Policy Change in the Marketing Mix: Learning from Proctor \& Gamble's Value Pricing Strategy," Journal of Marketing, New York; Jan, pp. 44-61, 2001.

3. Assael, H., Consumer Behavior \& Marketing Action, fourth edition, Boston, MA: PWS-Kent Publishing Company, 1992.

4. $\quad$ Baker, W. E. and W. L. Wilkie, "Factors Affecting Information Search for Consumer Durables," Working Paper 92-115, Marketing Science Institute, Cambridge, Massachusetts, May,1992. 
5. Belonax, J. A. and R. A. Mittelsteadt, "Evoked sets Size as a Function of Number of Choice Criteria and Information Variability." in Advances in Consumer Research, Vol. 5, ed. H. K. Hunt. Ann Arbor, MI. Association for Consumer Research, pp. 48-51, 1978.

6. Brown, J. and A. R. Wildt, "Evoked set Measurement," Journal of the Academy of Marketing Science, 20 (summer), pp. 235-243, 1992.

7. Campbell, B. M., "The Existence of Evoked sets and Determinants of Its Magnitude in Brand Choice Behavior," unpublished doctoral dissertation, Columbia University, 1969.

8. Clark, T., "International Marketing and National Character: A Review and Proposal for an Integrative Theory," Journal of Marketing, 54 (October), pp. 66-79, 1990.

9. Cook, T.D. and D. T. Campbell, Quasi-Experimentation: Design \& Analysis Issues for Field Settings, Boston, MA: Houghton Mifflin, 1979.

10. Dawar, N. and P. Parker, "Marketing Universals: Consumers' Use of Brand Name, Price, Physical Appearance, and Retailer Reputation as Signals of Product Quality," Journal of Marketing, 58 (April), pp. 81-95, 1994.

11. Engel, J. F., R. D. Blackwell, and P. W. Minard, Consumer Behavior, seventh edition, Fort Worth, TX: The Dryden Press, 1993.

12. Green, R. and E. Langeard, "A Cross-National Comparison of Consumer Habits and Innovator Characteristics," Journal of Marketing, 49 (July) pp. 34-41.

13. Gronhaug, K. (1973/74), "Some Factors Influencing the Size of Buyers Evoked sets," European Journal of Marketing, 7 (winter), pp. 232-41, 1975.

14. _ _ _ and S.V. Troye, "Exploring the Content of the Evoked sets in Car Buying," European Journal of Marketing, 11 (3), pp. 98-104, 1983.

15. Hauser, J. R. and B. Wernerfelt, "An Evaluation Cost Model of Evoked sets," Journal of Consumer Research, 16 (March), pp. 393-408, 1990.

16. Hite, R.E. and C. Fraser, "International Advertising Strategies of Multinational Corporations," Journal of Advertising Research, (August/September), pp. 9-17, 1988.

17. Howard, J. A., Marketing Management: Analysis and Planning, Homewood, Illinois: Richard D. Irwin Company, 1963.

18. Howard, J. A. and J. N. Sheth, The Theory of Buyer Behavior, New York: Wiley and Sons, 1969.

19. James, W. L. and J. S. Hill, "International Advertising Messages," Journal of Advertising Research, (June/July), pp. 65-71, 1991.

20. Jarvis, L. P. and J. B. Wilcox, "Evoked sets Size- Some Theoretical Foundations and Empirical Evidence," in Combined Proceedings of the Fall Conference of the American Marketing Association, vol. 35, Ed. T. V. Greer, Chicago: American Marketing Association, pp. 236-40, 1973.

21. Kale, S. H. and D. Sudharshan, "A Strategic Approach to International Segmentation," International Journal of Advertising, 2 (3), pp. 147-57, 1987.

22. Kanso, A., "International Advertising Strategies," Journal of Advertising Research, (January/February), pp. 10-14, 1992.

23. Lapersonne, E., G. Laurent, and J. LeGoff, "Evoked sets of size one: An empirical investigation of automobile purchases," International Journal of Research in Marketing, 12, pp. 55-66, 1995.

24. LeBlanc, R. P. and L. W. Turley, "Retail Influence on Evoked sets Formation and Choice of Shopping Goods," International Journal of Retail and Distribution Management, 22 (7), pp. 10-17, 1994.

25. __ _ _ _ Exploratory Investigation of Consumer Decision Making in the Service Sector," Journal of Services Marketing, 7 (4), pp. 1-18, 1993.

26. Lorimer, E., and W. Dunn, "Four Measures of Cross-Cultural Marketing Effectiveness," Journal of Advertising Research, 8 (1), pp. 11-13, 1968.

27. May, F. E. and R. Homans, "Evoked sets Size and the Level of Information Processing in Brand Comprehension and Choice Criteria." in Advances in Consumer Research. vol. 4, Ed. W. D. Perault. Association for Consumer Research, pp. 172-175, 1977.

28. McGowan, K.M. and B.J. Sternquist, "Dimensions of Price as a Marketing Universal: A Comparison of Japanese and U.S. Consumers," Journal of International Marketing, 6 (4), pp. 49-65, 1998.

29. Lorimer, E. S. and S. W. Dunn, "Four Measures of Cross-Cultural Marketing Effectiveness," Journal of Advertising Research, 8 (January), pp. 11-13, 1968. 
30. Narayana, C. L. and R. J. Markin, "Consumer Behavior and Product Performance: An Alternative Consideration," Journal of Marketing, 39 (fall), pp. 1-6, 1975.

31. Ostlund, L. E., "Evoked sets Size: Some Empirical Results," in Increasing Marketing Productivity and Conceptual and Methodological Foundations of Marketing (AMA Combined Proceedings), Vol. 35, ed. Thomas V. Greer, Chicago: American Marketing Association, pp. 226-230, 1973.

32. Pettit, K. L., S.L. Sawa, and G. H. Sawa, "Frugality: A Cross-National Moderator of the Price-Quality Relationship," Psychology and Marketing, 2 (4), pp. 9-15, 1985.

33. Silk, A. J., and G. L. Urban, "Pre-Test Market Evaluation of New Packaged Goods: A Model and Measurement Methodology," Journal of Marketing Research, 15 (May), pp. 171-191, 1978.

34. Shocker, A. D., M. Ben-Akiva, B. Boccara, and P. Nedungadi, "Evoked set Influences on Customer Decision-Making and Choice: Issues, Models, and Suggestions," Marketing Letters, 2 (August), pp. 181198, 1991.

35. Turley, L.W. and R. P. LeBlanc, "Evoked sets: A Dynamic Process Model," Journal of Marketing Theory and Practice, 3 (2), pp. 28-36, 1995.

36. Webster, C. "The Effects of Hispanic Subcultural Identification on Information Search Behavior," Journal of Advertising Research, 32 (Sept/Oct), pp. 54-62, 1992.

37. Wilkie, W., Consumer Behavior, third edition, New York, NY: John Wiley \& Sons, Inc., 1994. 